ADALAH : Buletin Hukum \&

Keadilan

Buletin Hukum \& Keadilan

@adalahuinjkt

\title{
Frase 'Antara Lain' Sebagai Awal Alasan Yang Lain Dalam Pembatalan Putusan Arbitrase
}

\author{
Siti Romlah*
}

Manusia adalah makhluk sosial yang selalu membutuhkan manusia lainnya untuk bertahan hidup. Oleh sebab itulah Aristoteles menyebut manusia dengan "zoon politicon." Memang menjadi sesuatu yang tidak dapat dipungkiri lagi, bahwa manusia memang tidak akan mampu untuk hidup sendiri, mereka akan mencari teman yang akan membantu diri mereka untuk memenuhi kebutuhan mereka. Namun, dalam dinamika sosial tersebut, manusia tak jarang untuk mengedepankan kebutuhan mereka dibanding dengan manusia lainnya, karena sifat egosentris yang mereka miliki. Karena itu juga Thomas Hobbes menyebut manusia dengan Homo Homini Lupus (manusia adalah serigala bagi manusia yang lainnya). Sifat egosentris merekalah yang terkadang menimbulkan perbedaan dan perselisihan antar sesama manusia, atau yang disebut dengan sengketa.

Sengketa dalam KBBI edisi $\mathrm{V}$ diartikan dengan perbedaan pendapat, pertikaian, perselisihan. Terdapat dua macam cara untuk menyelesaikan suatu sengketa, yaitu penyelesaian sengketa melalui pengadilan (litigasi) dan penyelesaian sengketa diluar pengadilan (non-litigasi). Penyelesaian sengketa melalui pengadilan (litigasi) adalah suatu proses penyelesaian sengketa, dimana kedua pihak yang saling

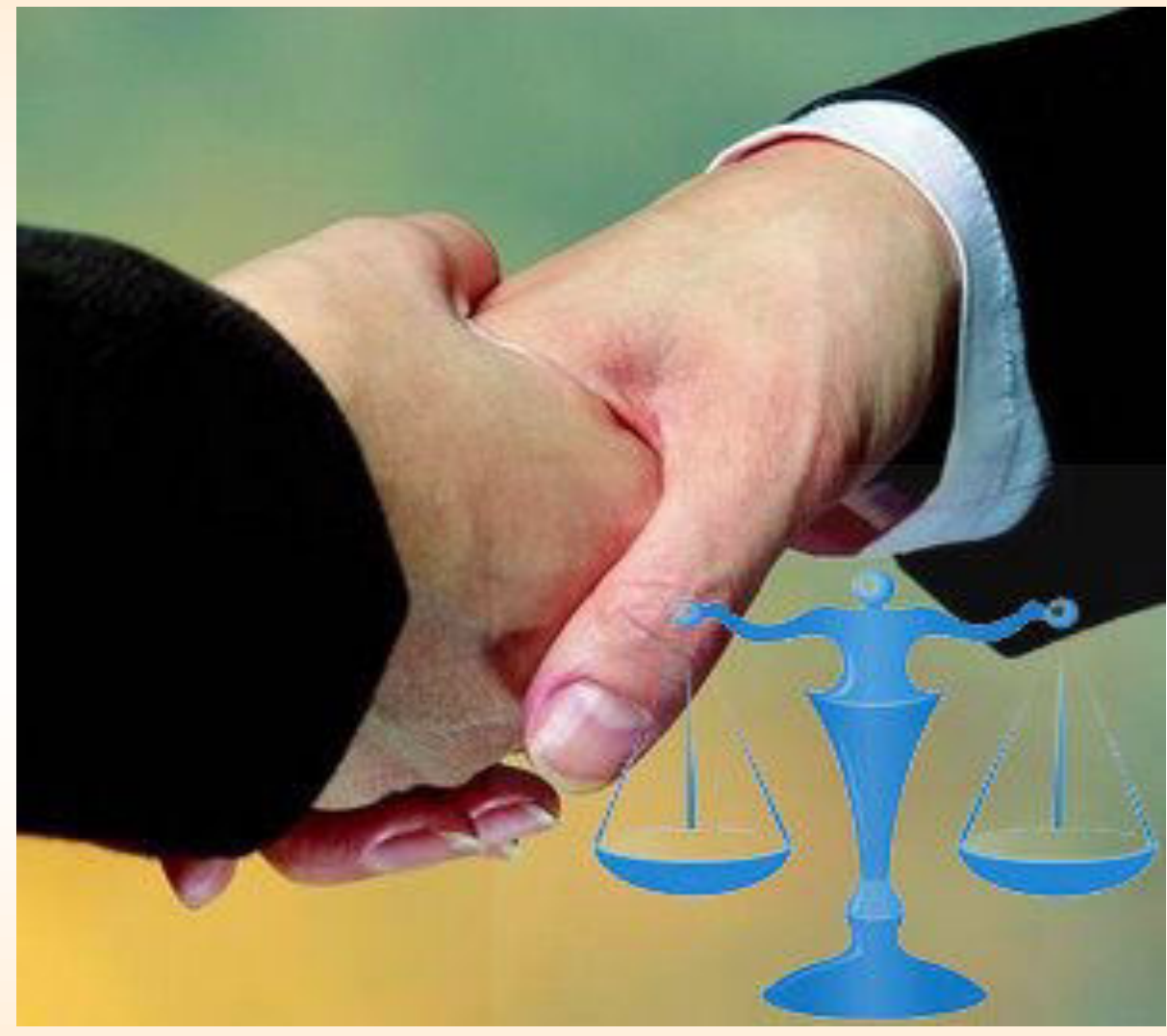

bersengketa dihadapkan atau pengadilan. Dalam pasal 1 angka 1 penyelesaian sengketanya Undang-Undang Nomor 30 Tahun dilakukan di pengadilan (Winarta, 1999 menyebutkan bahwa arbitrase 2012: 1-2). Sedangkan yang adalah suatu cara penyelesaian dimaksud dengan penyelesaian sengketa di luar peradilan umum sengketa di luar pengadilan adalah yang didasarkan pada perjanjian proses penyelesaian sengketa yang arbitrase yang dibuat secara tertulis dilakukan di luar pengadilan. oleh para pihak yang bersengketa. Penyelesaian sengketa di luar Kekuatan dari putusan arbitrase pengadilan menurut Undang- juga final dan binding, serta Undang Nomor 30 tahun 1999 dilakukan secara tertutup, sehingga dapat berbentuk konsultasi, negosiasi, konsiliasi, arbitrase, dan mediasi.

Arbitrase merupakan salah satu bentuk penyelesaian di luar banyak pelaku-pelaku usaha yang lebih memilih untuk menyelesaikan sengketa mereka dengan menggunakan arbitrase. Hal tersebut terjadi karena banyak perusahaan-perusahaan yang ingin 
menjaga nama baik perusahaan mereka. Muhammad Ardyansah dalam tulisannya menyebutkan bahwa:

“...tidak semua putusan yang dihasilkan melalui arbitrase akan memberikan kepuasan kepada para pihak. Ada kalanya putusan arbitrase tidak dilaksanakan secara sukarela oleh para pihak. Hal itu bisa disebabkan karena ada hal-hal dalam putusan sengketa diragukan keabsahannya atau ada alasan lain. Dalam hal ini, pengadilan memiliki peran yang besar dalam mengembangkan arbitrase (Andriansyah, 2014: 332)."

Hal-hal yang dapat menjadi alasan untuk mengajukan pembatalan putusan arbitrase, telah diatur dalam pasal 70 Undang-Undang Nomor 30 Tahun 1999, yaitu, pertama; adanya surat atau dokumen yang diajukan dalam pemeriksaan, setelah putusan dijatuhkan, diketahui ternyata dokumen atau surat tersebut palsu atau dinyatakan palsu; kedua, setelah adanya putusan arbitrase, ternyata ditemukan dokumen yang bersifat menentukan, yang disembunyikan oleh salah satu pihak; ketiga, setelah adanya putusan arbitrase, ternyata diketahui bahwa terdapat tipu muslihat yang dilakukan oleh salah satu pihak dalam pemeriksaan sengketa. Namun, yang menjadi permasalahan adalah dalam penjelasan umum Undang-Undang Nomor 30 Tahun 1999 menyebutkan unsur-unsur yang diperlukan untuk melakukan pembatalan putusan arbitrase, dengan frasa "antara lain."

Ilhami Ginang Pratidina menyebutkan dalam tulisannya "Frase 'antara lain' memiliki makna yang identik dengan terminologi 'inter alia' yang berarti '[a] mong other things' atau menyebut sebagian saja dari beberapa yang lain" (Pratidina, 2014: 311). Hal ini memberikan implikasi bahwa selain dari pada yang disebut dalam pasal 70 tersebut, berarti ada hal-hal lain yang dapat menjadi alasan lain untuk membatalkan putusan arbitrase. Dalam kenyataan, hal tersebut sudah pernah terjadi dan menjadi pertimbangan hukum majelis hakim Mahkamah Agung dalam perkara No. 03/ Arb.Btl/2005 tanggal 17 Mei 2006.

Frasa 'antara lain' tersebut sebaiknya harus segera diubah, agar nantinya tidak sembarangan dipergunakan untuk memasukkan alasan-alasan lain yang dapat membatalkan putusan arbitrase. UndangUndang Nomor 30 Tahun 1999 harus segera di revisi, bukan hanya permasalahan ini, namun juga dikarnakan banyak pasal-pasal yang sudah tidak sesuai lagi dengan perubahan zaman yang terjadi.

\section{Daftar Pustaka:}

*Penulis adalah anggota Permahi Tangerang sekaligus mahasiswa Ilmu Hukum UIN Syarif Hidayatullah Jakarta

Andriansyah, Muhammad. "Pembatalan Putusan Arbitrase Nasional oleh Pengadilan Negeri," Jurnal Cita Hukum, Volume I, Nomor 2, Desember 2014.

Aji, Ahmad Mukri. "Hak dan Kewajiban Asasi Manusia Dalam Perspektif Islam," SALAM: Jurnal Sosial dan Budaya Syar-i, Volume 2, Nomor 2, (2015). 